\title{
The global impact of adverse childhood experiences on criminal behavior: A cross-continental study
}

Miguel Basto-Pereira $^{\text {a, *, }}$ Maria Gouveia-Pereira ${ }^{\mathrm{b}}$, Cicero Roberto Pereira ${ }^{\mathrm{c}, \mathrm{d}}$, Emma Louise Barrett ${ }^{\mathrm{e}}$, Siobhan Lawler ${ }^{\mathrm{e}}$, Nicola Newton ${ }^{\mathrm{e}}$, Lexine Stapinski ${ }^{\mathrm{e}}$, Katrina Prior ${ }^{\mathrm{e}}$, Maria Suely Alves Costa ${ }^{\mathrm{f}}$, Jocélia Medeiros Ximenes ${ }^{\mathrm{f}}$, André Sousa Rocha ${ }^{\mathrm{f}}$, Grégory Michel ${ }^{\mathrm{g}, \mathrm{h}}$, Mathieu Garcia ${ }^{\mathrm{g}, \mathrm{h}}$, Emma Rouchy $^{\mathrm{g}, \mathrm{h}}$, Ameel Al Shawi ${ }^{i}$, Yassen Sarhan ${ }^{j}$, Celso Fulano ${ }^{k, 1}$, Angélica José Magaia ${ }^{\mathrm{m}}$, Sofián El-Astal ${ }^{\mathrm{n}}$, Kefaya Alattar ${ }^{\mathrm{n}}$, Khetam Sabbah ${ }^{\mathrm{n}}$, Leon Holtzhausen ${ }^{\mathrm{O}}$, Emma Campbell $^{\circ}$, Lidón Villanueva ${ }^{\mathrm{p}}$, Aitana Gomis-Pomares ${ }^{\mathrm{p}}$, Juan E. Adrián ${ }^{\mathrm{p}}$, Keren Cuervo $^{\mathrm{p}}$, Jaruwan Sakulku ${ }^{\mathrm{q}}$

${ }^{a}$ William James Center for Research, ISPA-Instituto Universitário, R. Jardim do Tabaco 34, 1100-304 Lisboa, Portugal.

b APPsyCI, ISPA - Intituto Universitário, R. Jardim do Tabaco 34, 1100-304 Lisboa, Portugal.

${ }^{\mathrm{c}}$ Institute of Social Sciences, University of Lisbon (ICS-ULisboa), Av. Prof. Aníbal Bettencourt 9, 1600-189, Lisbon, Portugal

${ }^{\mathrm{d}}$ Federal University of Paraíba, Campus I - Lot. Cidade Universitaria, PB 58051-900, Brazil

e The Matilda Centre for Research in Mental Health and Substance Use, University of Sydney, NSW 2006, Australia

${ }^{\mathrm{f}}$ Universidade Federal do Ceará, UFC, Campus Sobral, R. Cel. Estanislau Frota, 563 - Centro, Sobral, CE 62010-560, Brazil

${ }^{\mathrm{g}}$ Institut de Sciences Criminelles et de la Justice (ISCJ), University of Bordeaux, 4 rue du Maréchal Joffre, 1er étage, 33000 Bordeaux, France

${ }^{\mathrm{h}}$ Department of Psychology, University of Bordeaux, ISCJ, 4 rue du Maréchal Joffre, 33075 Bordeaux, France.

${ }^{\mathrm{i}}$ Department of Community \& Family Medicine, College of Medicine, University of Fallujah, Fallujah City, Anbar Governorate, Iraq

${ }^{\mathrm{j}}$ Department of Community \& Family Medicine, College of Medicine, University of Anbar, Ramadi city, Anbar Governorate, Iraq

${ }^{\mathrm{k}}$ Universidade Pedagógica, Rua João Carlos Raposo Beirão $n^{\circ}$ 135, Maputo, Mozambique

${ }^{1}$ Maputo Municipal Council, Bairro Chali, $n^{\circ} 142$, estrada 403, Maputo, Mozambique

${ }^{\mathrm{m}}$ Ministry of Gender, Children and Social Action, National Director of Children, Av Ahmed S Touré 908, Maputo, Mozambique.

${ }^{\mathrm{n}}$ Al Azhar University-Gaza, Jamal Abdl Naser St., Gaza, Palestine.

${ }^{\circ}$ Department of Social Development, University of Cape Town, Rondebosch, Cape Town 7700, South Africa

${ }^{\mathrm{p}}$ Developmental Psychology Department, Universitat Jaume I, Avda. Sos Baynat, $s / n$ 12071, Castellón, Spain

${ }^{\mathrm{q}}$ School of Psychology, Faculty of Liberal Arts, Thammasat University, 99 Moo 18 Paholyothin Rd. Khlong Nueng, Khlong Luang, Pathumthani 12121, Thailand

\section{A R T I C L E I N F O}

\section{Keywords:}

Cross-national study

Adverse childhood experiences

Child maltreatment

Criminal behavior

Young adulthood

\begin{abstract}
A B S T R A C T
Background: Adverse Childhood Experiences (ACEs) have been associated with a greater risk of later criminal offending. However, existing research in this area has been primarily conducted in Western developed countries and cross-cultural studies are rare.

Objectives: This study examined the relationship between ACEs and criminal behaviors in young adults living in 10 countries located across five continents, after accounting for sex, age, and cross-national differences.

Participants and setting: In total, 3797 young adults aged between 18 and 20 years (M = 18.97; DP

$=0.81$ ) were assessed locally in community settings within the 10 countries.
\end{abstract}

\footnotetext{
* Corresponding author.

E-mail address: miguelbastopereira@hotmail.com (M. Basto-Pereira).
} 
Method: The ACE Questionnaire was used to assess maltreatment and household dysfunction during childhood and a subset of questions derived from the Deviant Behavior Variety Scale (DBVS) was used to determine past-year criminal variety pertaining to 10 acts considered crime across participating countries.

Results: Physical and sexual abuse, physical neglect, and household substance abuse were related to criminal variety, globally, and independently across sexes and countries ranked differently in the United Nations Human Development Index (HDI). In addition, three out of five experiences of household dysfunction were related to criminal variety, but subsequent analyses indicate that some forms of household dysfunction only hold statistical significance among males or females, or in countries ranking lower in the HDI.

Conclusions: This research strengthens the finding that there are cross-cultural mechanisms perpetuating the cycle of violence. It also indicates that forms of household dysfunction have an impact on criminal behavior that is shaped by gender and the country's levels of social well-being.

\section{Introduction}

Adverse Childhood Experiences (ACEs) can be defined as stressful and potentially traumatic events that occur during the first 18 years of life (Dube et al., 2003). These experiences encompass different forms of abuse, neglect, and severe household dysfunction (Dube et al., 2003). Kessler et al. (2010) conducted one of the largest epidemiological surveys exploring the prevalence of ACEs among 51,945 adults in 21 countries participating in the WHO World Mental Health Surveys. Their findings revealed that childhood adversities are highly prevalent, with $38.8 \%$ of the sample having experienced at least one ACE before the age of 18 . The most common type of ACE reported was parental death (12.5\%), followed by physical abuse (8.0\%), parental divorce (6.6\%) and family violence (6.5\%). ACEs were also highly interrelated in this study. In other words, one child experiencing one type of adversity (e.g., physical or emotional abuse) has a substantially higher likelihood of experiencing other severe forms of adversity during childhood (e.g., exposure to domestic violence).

Abuse and neglect, which are found to be the most detrimental types of adversity, are particularly prevalent worldwide (Kessler et al., 2010; World Health Organization, 2020). Studies have indicated that the numbers of cases of child maltreatment identified and addressed by social care or justice professionals, are just the "tip of the iceberg". For example, a recent review of a series of metaanalyses (Stoltenborgh, Bakermans-Kranenburg, Alink, \& van IJzendoorn, 2015) combined and compared the prevalence of various types of child maltreatment across 244 reports and studies conducted globally. While the estimated prevalence in informant studies (mainly from official records) were less than a half percent (ranging from $0.3 \%$ for sexual abuse to $0.4 \%$ for physical and emotional abuse), a startling figure was found among self-report studies, where the estimated prevalence ranged from $12.7 \%$ for sexual abuse to 36.3\% for emotional abuse (Stoltenborgh et al., 2015).

A substantial number of studies (Hillis et al., 2004; Larkin, Shields, \& Anda, 2012) have also highlighted the negative effects of exposure to severe adversity during childhood on multiple long-term outcomes, including school failure, mental health problems, interpersonal dysfunction, and drug misuse. These outcomes, in turn, are risk factors for juvenile antisocial behavior and systemic obstacles to desist from crime during adulthood (Basto-Pereira \& Maia, 2017; Sampson \& Laub, 2005).

\subsection{Adverse childhood experiences and criminal behavior}

According to social learning theory, criminal behavior is learned and maintained by observing criminal behaviors and the social consequences attached to those behaviors (Akers, 2017; Felson \& Lane, 2009). The learning and acquisition of antisocial behavior is substantially more likely to occur during early developmental stages, particularly if the observed behavior is committed by people who are part of the individual's intimate social circle (Felson \& Lane, 2009). Since family members are the leading role models during child development, early adversity is particularly detrimental when it occurs within the family unit. Children can perceive violent and dysfunctional experiences (e.g., physical abuse, witnessing domestic violence, parental drug or alcohol misuse) as valid strategies to manage problems, particularly if those responsible for such violent behaviors were never stopped or, worse, if such violence against children is reinforced by other family members (Akers, 2017). Indeed, research has demonstrated that children who have been exposed to violence (e.g., exposure to domestic violence) or who have directly experienced adverse experiences such as physical or sexual abuse are more likely to perpetrate violent crime later in life.

One of the first groundbreaking studies describing this "cycle of violence", was conducted by Widom (1989) and involved following 1575 male children (667 from a control group) over the course of a 20 -year period after the report of child maltreatment. This study found that exposure to neglect or abuse increased the odds of a future arrest as a youth by $53 \%$ and as an adult by $38 \%$. More recently a meta-analysis (Braga, Gonçalves, Basto-Pereira, \& Maia, 2017) summarized subsequent longitudinal studies specifically addressing the link between different forms of child maltreatment and juvenile antisocial behaviors. This showed that the experience of physical, sexual, and emotional abuse and neglect substantially increased the odds of juveniles perpetrating aggressive antisocial acts. A subsequent meta-analysis also showed the enduring effects of maltreatment on antisocial behavior, persisting from adolescence until adulthood (Braga, Cunha, \& Maia, 2018).

Regarding the sex-specific role of each ACE on criminal and antisocial behavior, divergent findings have been reported in the 
literature. In two meta-analyses (Braga et al., 2017; Wilson, Stover, \& Berkowitz, 2009), gender was not a statistically significant moderator between early adversity and antisocial behavior. However, other meta-analyses have found that the risk of violent outcomes after child maltreatment was higher among females (Fitton, Yu, \& Fazel, 2020). Unfortunately, none of these studies examined the specific role of gender on each form of child abuse or neglect and, more importantly, did not analyze (or control for) the role of household dysfunction during childhood on subsequent criminal behavior.

Recently, Leban and Gibson (2020) conducted a large study examining the associations between cumulative ACEs and delinquency among boys $(n=964)$ and girls $(n=947)$, aged from 9 to 15-year-old, from neighborhoods in Chicago. After controlling for a large set of risk and protective factors, they found that the ACE cumulative score was a significant risk factor for delinquency among both boys and girls. However, even after controlling for a range of other factors shown to be associated with delinquency (such as family attachment, parental warmth, parental supervision, and self-reported depression), the ACE cumulative score remained a significant predictor of delinquency only among boys. Taken together, these findings suggest that - for females in particular - the relationships between ACEs and delinquency might be mitigated or aggravated by other intervening factors, such as dysfunctional household environments.

\subsection{Literature shortcomings and the current study}

Systematic reviews have provided important insights in relation to the impact of child maltreatment on multiple outcomes, including antisocial behavior (Braga et al., 2017; Carr, Duff, \& Craddock, 2020; Fitton et al., 2020). However, the accuracy of these insights is limited by the number of empirical studies published or made available online (e.g., official reports), as well as the diversity of procedures and assessment tools used across studies. In addition, almost all existing studies have examined samples from a limited number of countries. For instance, Stoltenborgh et al. (2015) review of child maltreatment prevalence found that across 244 publications, approximately only $20 \%$ of studies were conducted outside North America or Europe. Meta-analyses such as these, which are a key methodology to defining global policies, are mostly based on data from two continents and from a very specific segment of the world population: individuals from developed Western nations. Therefore, it is critical to examine the impact of different forms of early adversity across countries and from culturally specific perspectives to obtain more balanced and generalizable findings.

Cross-national research on risk factors for criminal offending is infrequent and usually limited to comparing two countries or three Western countries (Farrington, 2015). To our knowledge, there are no large cross-national studies exploring the link between the different forms of ACEs and criminal offences.

Recently, The International Study of Pro/Antisocial Behavior in Young Adults was created with the aim of overcoming these shortcomings in the existing literature (Basto-Pereira, Queiroz-Garcia, Maciel, Leal, \& Gouveia-Pereira, 2020). This study is a cross-national collaborative research project that involves the collection of self-report data from young adults (18-20 years old) living in 10 countries across five continents (Basto-Pereira et al., 2020). Self-report data from young adults is advantageous because recollection of more recent experiences of early adversity can improve accuracy (Paz-Alonso \& Goodman, 2008). In addition, criminal variety, also evaluated in this study, is considered one of the best indicators of criminal behavior, combining the frequency and seriousness about the different forms of delinquent behavior (Sanches, Gouveia-Pereira, Marôco, Gomes, \& Roncon, 2016). Indeed, this age group (18 to 20 years) is particularly relevant for this study, since offending reaches its peak between the end of adolescence and beginning of adulthood (Stolzenberg \& D'Alessio, 2008).

Therefore, the aim of this study is to explore whether each of the 10 ACEs (including child abuse, neglect, and household dysfunction) is associated with criminal variety during emerging adulthood, after accounting for biological sex and vastly different cultural and economic backgrounds from 10 countries across five continents. In addition, we aim to explore whether each ACE is independently associated with criminal behavior among both males and females and across young adults living in countries with varying levels of social well-being and development (United Nations Development Programme (UNDP), 2019).

\section{Methods}

\subsection{Participants and procedures}

The present study used cross-sectional data collected as part of the International Study of Pro/Antisocial Behavior in Young Adults (Basto-Pereira et al., 2020).

This includes a cross-national sample of young adults living in 10 countries (Portugal, Spain, France, Mozambique, South Africa, Brazil, Iraq, Palestine, Thailand, and Australia) across five continents (Europe, Africa, South America, Asia, and Australia). Individuals with less than four years of schooling, with difficulties in reading or understanding the native language, and serious psychopathology or cognitive deficit were excluded.

A total of 4182 young adults aged 18-20 years were recruited from the community. This age interval was chosen to capture the critical development period of transition to adulthood, when offending behavior typically reaches its peak (Stolzenberg \& D'Alessio, 2008), as well as to reduce the recall bias related to adversity experienced during the first 18 years of life (Paz-Alonso \& Goodman, 2008). Approximately $91 \%$ (90.8\%) of those recruited completed the entire questionnaire used in this study, resulting in a total sample of 3797 young adults: 2582 females (68.0\%) and 1215 males (32.0\%).

The majority of the sample were students $(74.8 \%)$, with a mean age of 18.97 years $(S D=0.81)$. The age balance was nearly perfect across the whole sample, with $34.29 \%$ of participants who were 18 years old, $34.29 \%$ who were 19 years old, and $31.42 \%$ who were 20 years old. The sample was also well-balanced within most of national samples, ranging between $20 \%-40 \%$ across each one of the three 
Table 1

Demographics, ACEs and criminal variety scores for samples in each participating country $(N=3797)$.

\begin{tabular}{|c|c|c|c|c|c|c|c|c|c|c|}
\hline Factor & Level & Portuga & & Spain & & France & & Iraq & & Palestine \\
\hline \multirow{3}{*}{ Sex, $n / \%$} & M & 205 & 36.35 & 176 & 37.37 & 66 & 13.87 & 147 & 38.99 & 44 \\
\hline & $\mathrm{F}$ & 359 & 63.65 & 295 & 62.63 & 410 & 86.13 & 230 & 61.01 & 157 \\
\hline & 18 & 230 & 40.78 & 164 & 34.82 & 133 & 27.94 & 131 & 34.75 & 51 \\
\hline \multirow[t]{2}{*}{ Age } & 19 & 179 & 31.74 & 186 & 39.49 & 158 & 33.19 & 161 & 42.71 & 77 \\
\hline & 20 & 155 & 27.48 & 121 & 25.69 & 185 & 38.87 & 85 & 22.55 & 73 \\
\hline \multirow[t]{2}{*}{ Education, $\mathrm{M} / \mathrm{SD}$} & & 11.39 & 1.30 & 12.55 & 1.09 & 12.94 & 1.82 & 12.09 & 0.33 & 12.65 \\
\hline & W & 50 & 8.88 & 13 & 2.77 & 4 & 0.85 & 3 & 0.80 & 0 \\
\hline \multirow{3}{*}{ Occupation } & $\mathrm{S}$ & 442 & 78.51 & 338 & 71.91 & 400 & 84.75 & 358 & 94.96 & 190 \\
\hline & WS & 57 & 10.12 & 95 & 20.21 & 63 & 13.35 & 15 & 3.98 & 9 \\
\hline & NWS & 14 & 2.49 & 24 & 5.11 & 5 & 1.06 & 1 & 0.27 & 2 \\
\hline Physical Abuse, $n$ / \% & & 53 & 9.40 & 78 & 16.56 & 113 & 23.74 & 68 & 18.04 & 41 \\
\hline Sexual Abuse, $n / \%$ & & 70 & 12.41 & 46 & 9.77 & 49 & 10.29 & 30 & 7.96 & 22 \\
\hline Emotional Abuse, $n / \%$ & & 46 & 8.16 & 41 & 8.70 & 82 & 17.23 & 24 & 6.37 & 20 \\
\hline Physical Neglect, $n$ / \% & & 34 & 6.03 & 31 & 6.58 & 33 & 6.93 & 76 & 20.16 & 65 \\
\hline Emotional Neglect, $n / \%$ & & 51 & 9.04 & 51 & 10.83 & 59 & 12.39 & 87 & 23.08 & 56 \\
\hline Divorce/ Separation, $n$ / \% & & 184 & 32.62 & 118 & 25.05 & 168 & 35.29 & 17 & 4.51 & 16 \\
\hline Exposure to Domestic Violence, $n / \%$ & & 70 & 12.41 & 33 & 7.01 & 52 & 10.92 & 62 & 16.45 & 47 \\
\hline Substance Ab. HH, $n$ / \% & & 128 & 22.70 & 86 & 18.26 & 124 & 26.05 & 13 & 3.45 & 14 \\
\hline Mental ill. HH, $n$ / \% & & 154 & 27.30 & 128 & 27.18 & 189 & 39.71 & 32 & 8.49 & 27 \\
\hline Incarc. $\mathrm{HH}, n / \%$ & & 25 & 4.43 & 23 & 4.88 & 19 & 3.99 & 23 & 6.10 & 36 \\
\hline ACE Total, M / SD & & 1.45 & 1.73 & 1.35 & 1.61 & 1.87 & 1.85 & 1.15 & 1.56 & 1.71 \\
\hline Criminal Variety, M/SD & & 0.93 & 1.46 & 1.46 & 1.85 & 2.79 & 3.52 & 0.72 & 1.22 & 1.24 \\
\hline HDI & Index & 0.85 & & 0.89 & & 0.89 & & 0.69 & & 0.69 \\
\hline
\end{tabular}

Note. $\mathrm{M}=$ Males; F = Female; $\mathrm{W}=$ Only working; $\mathrm{S}=$ Only studying; WS=Working and Studying; NWS = Not Working or Studying; Substance Ab. $\mathrm{HH}=$ Substance Abuse in the household; Mental ill. $\mathrm{HH}=$ Mental illness in the Household; Incarc. HH = Incarcerated Household Member; ACE = Adverse Childhood Experience; HDI = Human Development Index.

age groups. The exception was the sample collected in Brazil, where the distribution of age groups ranged between $16.85 \%$ (20 years old) to $61.41 \%$ (18 years old). With regard to gender balance, the proportion of males was always higher than $25 \%$, apart from Palestine (21.89\% males; $n=44)$ and France (13.87\% males; $n=66)$, where the gender imbalance was more pronounced. The sociodemographic characteristics, ACEs, and criminal variety scores are provided in Table 1 for the whole sample and country-bycountry.

Young adults were recruited from community settings including universities, vocational schools, workplaces, sport organizations, high schools, or online in the included countries, using convenience and snowball sampling methods. In order to conduct this research project in multiple countries, an international network of researchers based across 10 countries was established. Researchers who agreed to participate received a set of guidelines containing detailed information about the methods and procedures to be implemented across countries, including information about the aims of this project, inclusion/exclusion criteria, informed consent forms, measures, and ethical issues (for a full description see Basto-Pereira et al., 2020).

The questionnaires included in this cross-national initiative, which had not been previously adapted for each country, were translated, back-translated, and adapted for multiple languages, including English, French, Spanish, Portuguese, Arabic, Thai, and Afrikaans. Preferential criteria were established across sites for a balanced sample regarding sex, age, and occupation. Due to the age range, a majority of students was expected, but the importance of representing other groups was stressed (e.g., workers/ student-workers).

Participating countries were selected to represent markedly different political, cultural, religious, and economic realities, and from different, and understudied, geographic regions across the globe, in order to explore the cross-cultural impact of ACEs on antisocial patterns in early adulthood. The overall sample of male and female participants, while homogenous regarding the developmental period under study (young adulthood), is markedly heterogenous in terms of participants' cultural, economic, and religious backgrounds. This diversity provides the opportunity to explore the cross-cultural implications of ACEs on early adulthood, apart from the High-Income Western context, in one of the most culturally diverse cross-national studies in this field.

This global study was approved by the ISPA-Instituto Universitário Ethics Committee in Lisbon, Portugal. In addition, all required legal and ethical authorizations were requested and obtained in participating countries before data collection commenced in each country. Participants provided informed consent at the time of data collection, and after the aims of this research project were explained and confidentiality was guaranteed. A full description of the procedures and ethical issues of this cross-national initiative is provided in Basto-Pereira et al. (2020).

\subsection{Measures}

2.2.1. Human Development Index (HDI; United Nations Development Programme (UNDP), 2019)

The index was created by the United Nations to rank countries according to three dimensions: education (mean years of schooling; expected years of schooling), health (life expectancy at birth), and a decent standard of living (gross national income per capita). The 


\begin{tabular}{|c|c|c|c|c|c|c|c|c|c|c|c|c|}
\hline \multirow{2}{*}{$\frac{\text { Palestine }}{21.89}$} & \multicolumn{2}{|c|}{ Thailand } & \multicolumn{2}{|c|}{ Australia } & \multicolumn{2}{|l|}{ Brazil } & \multicolumn{2}{|c|}{ Mozambique } & \multicolumn{2}{|c|}{ South Africa } & \multicolumn{2}{|l|}{ Total } \\
\hline & 113 & 26.90 & 118 & 25.43 & 102 & 55.43 & 138 & 43.40 & 106 & 32.92 & 1215 & 32.00 \\
\hline 78.11 & 307 & 73.10 & 346 & 74.57 & 82 & 44.57 & 180 & 56.60 & 216 & 67.08 & 2582 & 68.00 \\
\hline 25.37 & 83 & 19.76 & 183 & 39.44 & 113 & 61.41 & 124 & 38.99 & 90 & 27.95 & 1302 & 34.29 \\
\hline 38.31 & 171 & 40.71 & 147 & 31.68 & 40 & 21.74 & 86 & 27.04 & 97 & 30.12 & 1302 & 34.29 \\
\hline 36.32 & 166 & 39.52 & 134 & 28.88 & 31 & 16.85 & 108 & 33.96 & 135 & 41.93 & 1193 & 31.42 \\
\hline 0.98 & 12.38 & 0.87 & 12.67 & 1.59 & 13.92 & 2.05 & 11.26 & 1.64 & 11.70 & 0.65 & 12.27 & 1.48 \\
\hline 0.00 & 3 & 0.71 & 62 & 13.36 & 3 & 1.63 & 25 & 7.86 & 16 & 5.02 & 179 & 4.73 \\
\hline 94.53 & 392 & 93.33 & 152 & 32.76 & 125 & 67.93 & 231 & 72.64 & 207 & 64.89 & 2835 & 74.84 \\
\hline 4.48 & 23 & 5.48 & 226 & 48.71 & 55 & 29.89 & 35 & 11.01 & 83 & 26.02 & 661 & 17.45 \\
\hline 1.00 & 2 & 0.48 & 24 & 5.17 & 1 & 0.54 & 27 & 8.49 & 13 & 4.08 & 113 & 2.98 \\
\hline 20.40 & 40 & 9.52 & 93 & 20.04 & 25 & 13.59 & 44 & 13.84 & 143 & 44.41 & 698 & 18.38 \\
\hline 10.95 & 47 & 11.19 & 73 & 15.73 & 30 & 16.30 & 115 & 36.16 & 87 & 27.02 & 569 & 14.99 \\
\hline 9.95 & 24 & 5.71 & 96 & 20.69 & 33 & 17.93 & 42 & 13.21 & 99 & 30.75 & 507 & 13.35 \\
\hline 32.34 & 82 & 19.52 & 58 & 12.50 & 34 & 18.48 & 133 & 41.82 & 145 & 45.03 & 691 & 18.20 \\
\hline 27.86 & 77 & 18.33 & 72 & 15.52 & 39 & 21.20 & 70 & 22.01 & 117 & 36.34 & 679 & 17.88 \\
\hline 7.96 & 86 & 20.48 & 165 & 35.56 & 53 & 28.80 & 99 & 31.13 & 138 & 42.86 & 1044 & 27.50 \\
\hline 23.38 & 49 & 11.67 & 55 & 11.85 & 37 & 20.11 & 112 & 35.22 & 129 & 40.06 & 646 & 17.01 \\
\hline 6.97 & 118 & 28.10 & 132 & 28.45 & 87 & 47.28 & 140 & 44.03 & 153 & 47.52 & 995 & 26.20 \\
\hline 13.43 & 57 & 13.57 & 278 & 59.91 & 58 & 31.52 & 72 & 22.64 & 175 & 54.35 & 1170 & 30.81 \\
\hline 17.91 & 22 & 5.24 & 12 & 2.59 & 13 & 7.07 & 73 & 22.96 & 76 & 23.60 & 322 & 8.48 \\
\hline 1.76 & 1.43 & 1.51 & 2.23 & 2.13 & 2.22 & 1.97 & 2.83 & 2.13 & 3.92 & 2.75 & 1.93 & 2.05 \\
\hline 1.60 & 0.68 & 1.26 & 0.91 & 1.31 & 1.04 & 1.35 & 1.21 & 1.76 & 2.26 & 2.59 & 1.34 & 2.09 \\
\hline 0.69 & 0.77 & & 0.94 & & 0.76 & & 0.45 & & 0.71 & & & \\
\hline
\end{tabular}

HDI ranges between 0 and 1, and it is considered one of the best indicators summarizing the social well-being and life satisfaction in each country (Ngoo \& Tey, 2019).

\subsubsection{ACE Questionnaire (Dube et al., 2003)}

This self-report questionnaire was used to evaluate 10 different ACEs experienced during the first 18 years of life, including abuse, neglect, and household dysfunction (Dube et al., 2003). (e.g., "Did an adult or older relative, family friend, or stranger ever touch or fondle your body in a sexual way?); two items evaluating physical abuse (e.g., "How often did a parent, step-parent, or adult living in your home actually push, grab, shove, slap you, or throw something at you?"); and two items evaluating emotional abuse (e.g., "How often did a parent, step-parent, or adult living in your home swear at you, insult you, or put you down?"). Due to a translation disparity between the existing Portuguese version of the ACE questionnaire and the international version, written instructions regarding physical and emotional abuse in Portugal, Brazil, and Mozambique did not clearly state that the acts of abuse were committed by a family member. In order to standardize the questionnaire with the remaining countries, for these three countries an additional question was used to check if acts of physical and emotional abuse were committed by family members or someone living in the same house during the first 18 years of life. When this was not the case, that form of family abuse was considered absent. Five items evaluated physical neglect (e.g., "I didn't have enough to eat"), and five additional items evaluated emotional neglect (e.g., "People in my family looked out for each other"; reverse scored). One of the five questions evaluating child physical neglect is formulated in a slightly different way in Mozambique and Brazil (e.g., "There was someone in my house who did the laundry"; Reversed) than in the remaining countries (e.g., "I had to wear dirty clothes"). All the remaining questions and instructions for abuse, neglect, and household dysfunction were identical across countries. In addition, five different forms of household dysfunction were evaluated: (i) four items evaluated exposure to domestic violence against the mother/stepmother; (ii) one item evaluated parental divorce or separation; (iii) one item evaluated experiences related to incarceration; (iv) one item evaluated mental illness in the household; and (v) two items evaluated substance abuse of an adult family member living in the same house. Child abuse and neglect $(1=$ Never to $5=$ Very often) and exposure to domestic violence $(1=$ Never true to $5=$ Very often true) were evaluated using a five-point Likert scale, while questions regarding the remaining experiences were evaluated using a dichotomous ("Yes $=1$ " or "No $=0$ ") response style. The ACE questionnaire was scored, and each of the above experiences were classified "present" or "absent", according to the authors' recommendations (Dube et al., 2003). The ACE Total was calculated summing all the present ACEs.

\subsubsection{Criminal Variety Index (CVI)}

The CVI aims to assess the variety of criminal acts committed during the last year. The CVI was built using the DBVS questionnaire (Sanches et al., 2016), a 19-item self-report questionnaire that evaluates the commission of different deviant behaviors during last year, using a dichotomous ("Yes $=1$ " or "No $=0$ ") response format. To build the CVI, non-illegal deviant acts (e.g., school truancy, lying) or acts that are not consistently classified as illegal acts in the included countries (e.g., drug use in Portugal) were excluded. Ten out of 19 items presented in the DBVS questionnaire and evaluating the commitment of behaviors, consistently classified as illegal across countries included in this collaborative research project, were used in the present study. Those items evaluated different types of crimes with varying levels of seriousness, including property damage ("Damaged or destroyed public or private property?"; "Done 
Table 2

Model comparison between the intercept model and the final model, by sex and human development index.

\begin{tabular}{|c|c|c|c|c|c|c|c|c|c|c|c|c|c|c|c|}
\hline \multirow[b]{4}{*}{ Models } & & & & \multicolumn{12}{|c|}{ Criminal Variety } \\
\hline & & & & \multicolumn{6}{|l|}{ Sex } & \multicolumn{6}{|c|}{ Human Development Index (HDI) } \\
\hline & \multicolumn{3}{|l|}{ Total } & \multicolumn{3}{|l|}{ Male } & \multicolumn{3}{|l|}{ Female } & \multicolumn{3}{|c|}{$50 \%$ Top Tier } & \multicolumn{3}{|c|}{$50 \%$ Bottom tier } \\
\hline & AIC & BIC & $-2 \mathrm{LL}$ & AIC & BIC & $-2 \mathrm{LL}$ & AIC & BIC & $-2 \mathrm{LL}$ & AIC & BIC & $-2 \mathrm{LL}$ & AIC & BIC & $-2 \mathrm{LL}$ \\
\hline Intercept & $12,627.51$ & $12,628.41$ & $12,621.5$ & 4830.45 & 4831.36 & 4824.44 & 7579.48 & 7580.38 & 7573.48 & 7736.50 & 7735.33 & 7730.50 & 4892.12 & 4890.95 & 4886.12 \\
\hline Final & $11,205.11$ & $11,209.96$ & $11,173.12$ & 4244.85 & 4249.39 & 4214.86 & 6944.90 & 6949.44 & 6914.9 & 7165.32 & 7159.08 & 7133.32 & 4013.25 & 4007.00 & 3981.24 \\
\hline \multirow{2}{*}{ Model Comparison } & LRT & Df & $p$-value & LRT & Df & $\mathrm{p}$-value & LRT & Df & $\mathrm{p}$-value & LRT & Df & $\mathrm{p}$-value & LRT & Df & $\mathrm{p}$-value \\
\hline & 1448.39 & 13 & $<0.001$ & 609.6 & 12 & $<0.001$ & 658.58 & 12 & $<0.001$ & 597.17 & 13 & $<0.001$ & 904.88 & 13 & $<0.001$ \\
\hline
\end{tabular}

Note. AIC = Akaike Information Criterion; BIC $=$ Bayesian Information Criterion; $-2 \mathrm{LL}=-2$ Loglik; LRT $=$ Likelihood Ratio Test; $\mathrm{df}=$ degree of freedom. 
graffiti on buildings or other locations [e.g., school, public transports, walls, etc.]?"), different types of theft ("Used a motorbike or a car to go for a ride without the owner's permission?"; "Stolen something worth more than 50 euros?"; "Stolen something worth between 5 and 50 euros?"; "Stolen something worth less than 5 euros?"), driving without license ("Drove a motorbike or a car without having a driver's license?"), vehicle theft and burglary ("Broken into a car, house, shop, school, or other building?"), drug trafficking ("Sold drugs [e.g., hashish, marijuana, cocaine, ecstasy, amphetamines, etc.]?"), and aggression ("Hit an adult [e.g., teacher, family, security guard, etc.]?"). The CVI total score, ranging from 0 to 10, was obtained by summing answers to all these items.

\subsection{Analytic strategy}

This study adopted a negative-binomial multi-level model. This analytic strategy was chosen because the outcome is a count variable (number of different self-reported criminal acts committed during last year), is positively skewed, and is overdispersed, therefore negating the use of a Poisson multilevel regression model. In addition, multilevel models allowed for the testing of the impact of each ACE on criminal variety, after taking into account the data's clustered nature (i.e., the similarity between individuals residing in the same country; [Heck, Thomas, \& Tabata, 2013]). Since the focus of this study is the impact of individual-level factors (abuse, neglect, household dysfunction) on the outcomes (criminal variety), we opted to fit a random intercept model, analyzing the individual-level regression model after accounting for national/cultural-specific variables affecting the outcome. Since observations from the same country are expected to be more similar than observations from different countries, we calculated the Intraclass Correlation Coefficient (ICC), indicating the variance of criminal variety during last year, which accounted for living in different countries. Multilevel analyses were then performed in four different subsamples. First, a subsample of males and females, then this sample was split into two tiers using the HDI report list (United Nations Development Programme (UNDP), 2019) and separate multilevel analyses were conducted for those living in the highest versus lowest HDI half tier of countries (see Table 1). The GLMM adaptive package for $\mathrm{R}$ software was used for multilevel models. This $R$ package fits negative-binomial generalized linear mixed models using a Gauss-Hermitage quadrature for computation of the log-likelihood function (Bolker et al., 2009; Rizopoulos, 2020).

\section{Results}

The results section presents the fitted five negative binomial multilevel random-intercept models (Tables 2 and 3 ) for the: 1 ) total sample; 2) the subsample of males; 3) the subsample of females; 4) the HDI half top tier countries and; 5) the HDI half bottom tier countries. In each one of these models, we included all the predicting variables for the criminal variety. We compared each one of these models with the null model by using the Akaike Information Criterion (AIC), the Bayesian Information Criterion (BIC), and the deviance test.

Lower values of AIC and BIC were found for the final model when compared with the competing null model. In addition, all the deviance tests were statistically significant $(p<.01)$, consistently indicating a better fit for the final model. The ICC of the null model

Table 3

Multilevel negative binomial regression model predicting criminal variety by sex and human development index.

\begin{tabular}{|c|c|c|c|c|c|c|c|c|c|c|}
\hline \multirow[b]{4}{*}{ Predictors } & & & \multicolumn{8}{|c|}{ Criminal Variety } \\
\hline & & & \multicolumn{4}{|l|}{ Sex } & \multicolumn{4}{|c|}{ Human Development Index (HDI) } \\
\hline & \multicolumn{2}{|c|}{ Total $(N=3797)$} & \multicolumn{2}{|c|}{$\begin{array}{l}\text { Male } \\
(n=1215)\end{array}$} & \multicolumn{2}{|c|}{$\begin{array}{l}\text { Female } \\
(n=2583)\end{array}$} & \multicolumn{2}{|c|}{$\begin{array}{l}\text { Top tier } \\
(n=2396)\end{array}$} & \multicolumn{2}{|c|}{$\begin{array}{l}\text { Bottom tier } \\
(n=1402)\end{array}$} \\
\hline & $\operatorname{Exp}(\gamma)$ & SE & $\operatorname{Exp}(\gamma)$ & SE & $\operatorname{Exp}(\gamma)$ & SE & $\operatorname{Exp}(\gamma)$ & SE & $\operatorname{Exp}(\gamma)$ & SE \\
\hline & \multicolumn{10}{|c|}{ Fixed Effects } \\
\hline Intercept $\gamma_{00}$ & 1.15 & 0.16 & 1.19 & 0.15 & $0.54^{* *}$ & 0.17 & 1.35 & 0.26 & 0.94 & 0.13 \\
\hline Sex $=$ Female $\gamma_{10}$ & $0.50^{* *}$ & 0.05 & - & - & - & - & $0.53^{* *}$ & 0.07 & $0.46^{* *}$ & 0.07 \\
\hline Age $=19 \gamma_{20}$ & $1.10^{\dagger}$ & 0.06 & 1.05 & 0.08 & $1.14^{\dagger}$ & 0.08 & 1.08 & 0.07 & 1.14 & 0.08 \\
\hline Age $=20 \gamma_{30}$ & 0.99 & 0.06 & 1.02 & 0.08 & 1.00 & 0.08 & 0.99 & 0.08 & 1.02 & 0.08 \\
\hline Emotional Abuse $\gamma_{40}$ & 1.05 & 0.07 & 0.95 & 0.11 & 1.07 & 0.10 & 1.16 & 0.11 & 0.94 & 0.10 \\
\hline Physical Abuse $\gamma_{50}$ & $1.31^{* *}$ & 0.06 & $1.34^{* * *}$ & 0.09 & $1.38^{* *}$ & 0.09 & $1.21^{*}$ & 0.09 & $1.47^{* *}$ & 0.09 \\
\hline Sexual Abuse $\gamma_{50}$ & $1.42^{* *}$ & 0.06 & $1.29^{* * *}$ & 0.10 & $1.47^{* *}$ & 0.09 & $1.38^{* *}$ & 0.09 & $1.42^{* *}$ & 0.08 \\
\hline Emotional Neglect $\gamma_{60}$ & 1.04 & 0.07 & 1.03 & 0.09 & 1.08 & 0.09 & 1.03 & 0.10 & 1.05 & 0.08 \\
\hline Physical Neglect $\gamma_{70}$ & $1.35^{* *}$ & 0.07 & $1.26^{*}$ & 0.10 & $1.39^{\star *}$ & 0.10 & $1.30^{*}$ & 0.12 & $1.40^{* *}$ & 0.08 \\
\hline Divorce/Separation $\gamma_{80}$ & 1.00 & 0.05 & 0.96 & 0.08 & 1.03 & 0.07 & 1.04 & 0.07 & 0.94 & 0.08 \\
\hline Exposure to domestic violence $\gamma_{90}$ & $1.24^{* *}$ & 0.07 & 1.14 & 0.10 & $1.31^{\star *}$ & 0.09 & 1.08 & 0.10 & $1.36^{* *}$ & 0.08 \\
\hline Substance Abuse household $\gamma_{10} 0$ & $1.22^{* *}$ & 0.06 & $1.28^{* *}$ & 0.08 & $1.17^{*}$ & 0.08 & $1.22^{*}$ & 0.08 & $1.27^{* *}$ & 0.09 \\
\hline Mental illness in the household $\gamma_{110}$ & $1.15^{* *}$ & 0.05 & $1.16^{\dagger}$ & 0.08 & $1.17^{*}$ & 0.07 & 1.09 & 0.07 & $1.27^{* *}$ & 0.08 \\
\hline \multirow[t]{2}{*}{ Incarcerated household member $\gamma_{12} 0$} & $1.24 * *$ & 0.08 & $1.27^{*}$ & 0.11 & $1.22^{\dagger}$ & 0.12 & 1.18 & 0.15 & $1.21^{*}$ & 0.09 \\
\hline & \multicolumn{10}{|c|}{ Random Effects } \\
\hline $\operatorname{Var}\left(\right.$ Intercept) $\gamma_{0 j}$ & 0.22 & & 0.18 & & 0.23 & & 0.32 & & 0.06 & \\
\hline
\end{tabular}

Note. $\mathrm{SE}=$ Standard Error.

*** $\mathrm{p}<.01$.

* $\mathrm{p}<.05$.

$\dagger \mathrm{p}<.1$ 
indicated that country of residence accounted for $16.60 \%$ of self-reported criminal variety during last year, which was slightly lower in the subsample of HDI bottom-tier countries (13.80\%), and slightly higher for the models fitted in the subsamples of females (17.60\%), in the subsample of males (18.90\%), and in the subsample of HDI top-tier countries $(19.20 \%)$.

As illustrated in Table 3, seven ACEs were significantly associated with criminal variety during the last year for the full sample, while six ACEs were significantly or marginally significant for male and female young adults. In addition, from our sample of countries, the same four ACEs significantly predicted criminal variety in young adults living in the countries with the HDI half top tier countries and in the HDI half bottom tier countries. Physical abuse, sexual abuse, physical neglect, and household substance abuse during the first 18 years of life were positively associated with criminal variety during the last year among males and females aged 18-20 years old and living in countries ranking differently in the HDI composite measure.

Sexual abuse was the strongest predictor of criminal variety during last year. Compared to non-sexually abused individuals, the number of self-reported criminal variety during last year was $42 \%$ higher $(\exp (\gamma)=1.42, p<.001)$ for the full sample, $29 \%$ higher (exp $(\gamma)=1.29, p<.001)$ among the male subsample, and $47 \%(\exp (\gamma)=1.47, \mathrm{p}<.001)$ higher among the female subsample. While sexual abuse was the strongest predictor of criminal variety for females and young adults living in HDI-defined top-tier countries, physical abuse was the strongest predictor of criminal variety among males and young adults living in the HDI bottom tier countries. A detailed description of the estimated parameters by the multilevel negative binomial regression model predicting criminal variety is presented in Table 3.

\section{Discussion}

The main aim of this study was to explore whether the various forms of early adversity are risk factors for criminal behavior among young adults living in ten countries across the globe from substantially different religious, economic, and cultural backgrounds. To our knowledge this is the first study exploring the intercultural relationship between each ACE and criminal outcomes, using a truly crosscultural design that include countries from five continents.

\subsection{Child maltreatment and criminal behavior}

One of the most interesting findings of this study indicates physical abuse, physical neglect, and sexual abuse are, consistently, predictors of criminal variety, independently across male and female young adults and living in countries whose ranking is markedly different in respect to education, income, and national health indicators. This is in line with two meta-analyses that have shown a link between these forms of child maltreatment and antisocial outcomes during adolescence and adulthood (Braga et al., 2017; Cottle, Lee, \& Heilbrun, 2001).

Several studies suggest that severe adversity during childhood is linked to the development of psychopathic traits (e.g., BaskinSommers \& Baskin, 2016; Blair \& Lee, 2013) and it is a known risk factor for the development of antisocial personality disorder during adulthood (e.g., Douglas et al., 2011). In fact, from a psychobiological perspective, children continuously facing dangerous environments, such as persistent physical or sexual abuse, may develop a low responsivity to stress to adapt to persistent severe stress (Young-Southward, Svelnys, Gajwani, Enlow, \& Minnis, 2020). Hyporesponsivity is linked to low sensitivity to threats, risk taking and inability to proper understand and react to social feedback (Glenn, 2019; Young-Southward et al., 2020). This pattern of generalized low responsivity - usually referred to as the unemotional pattern — generates low arousal and fearlessness that facilitate transgressive and violent conducts (Glenn, 2019).

Experiences of physical and sexual abuse can also generate strong negative experiences (e.g., anger, rage, sensation of entrapment), creating the desire for retaliation and revenge and increasing the likelihood of delinquent behavior as a way to cope (Agnew, 2006). In addition, children who were victims of severe abuse (particularly abuse perpetrated against them by meaningful role models) may learn those behaviors as acceptable ways to respond to similar situations later in life (Akers, 2017). Conduct problems that can develop are not restricted to the simple replication of the violence suffered, they can also be other forms of delinquent behavior that are perpetuated throughout life (Felson \& Lane, 2009).

Interestingly, child sexual abuse among females was the strongest predictor of criminal behavior in this study. The predictor effect size was weaker among males than females. This is in line with previous research showing that sex moderates the relationship between child sexual abuse and later criminal outcomes (Papalia, Ogloff, Cutajar, \& Mullen, 2018). This may be explained by research illustrating that female victims are more likely than male victims to have experienced more severe (e.g., sexual abuse involving penetration or attempted penetration), and chronic experiences of sexual abuse, and have a greater likelihood of self-blaming immediately postassault (Ullman \& Filipas, 2005).

This helps to explain why females are at higher risk of developing post-traumatic stress disorder, which may include symptoms of irritability, aggression, risky or destructive behavior, and hypervigilance (Swan, Gambone, Fields, Sullivan, \& Snow, 2005). Additionally, the experience of chronic sexual abuse increases risk for the development of a range of other mental health disorders and disruptions across many domains of functioning (McLean \& Gallop, 2003). In cases of family sexual abuse, for instance, females are more likely to run away from home and to be homeless when compared with males, which may increase risk of school failure, deviant peer affiliation and an early justice involvement (e.g., Tyler, Hoyt, Whitbeck, \& Cauce, 2001).

Physical neglect was also independently related to criminal variety across males and females and across countries with different levels of social well-being (according the HDI ranking). There are several potentially causal links between physical neglect and later maladjusted behavior. Inappropriate nutrition impacts child brain development, affecting behavior, and cognitive and learning skills (Galler et al., 2011). In addition, the lack of structured daily routines and parental supervision that characterizes physical neglect, can 
affect emotional regulation and ability or opportunity to model appropriate behavior (Bater \& Jordan, 2017; Flanagan, Auty, \& Farrington, 2019).

Surprisingly, emotional maltreatment (emotional abuse or emotional neglect) was not associated with criminal variety in this study. Contrary to these findings, the Braga et al. (2017) meta-analysis found a weak, but statistically significant, relationship between emotional abuse and antisocial behavior during adolescence. The overlap between emotional maltreatment and other forms of child maltreatment may blur our findings and the findings from meta-analyses. For example, the study conducted by Dong et al. (2004) with a large sample of adults $(N=8629)$, found that $98 \%$ of those reporting child emotional abuse and $93 \%$ of those reporting emotional neglect also reported other forms of childhood adversity. Thus, it is crucial to expand our knowledge about how cross-country differences may play a role on the impact of emotional maltreatment in the presence (and absence) of other forms of childhood adversity.

\subsection{The impact of childhood household dysfunction}

In the total sample, exposure to domestic violence, household substance abuse, household mental illness and having an incarcerated household member during the first 18 years of life were all significantly associated with criminal variety during young adulthood. The disruptive nature of these experiences may cause stigma, marginalization (e.g., Condry, 2007) and reduced family income (Gauffin, Hjern, Vinnerljung, \& Björkenstam, 2016). These ACEs can also affect the development of self-control among youth, an important predictor of deviant behavior (e.g., Gomes \& Gouveia-Pereira, 2020) and create conditions for learned maladaptive behaviors. More broadly, it can lead to insecure attachment styles, an important predictor of later antisocial traits and behaviors (e.g., Kochanska \& Kim, 2012).

However, less is known about the sex-specific impact of different forms of household dysfunction on criminal behavior. The analysis conducted separately for males and females reveals one of the most interesting findings of the current study. Three out of the five forms of household dysfunction during childhood (i.e., incarcerated household member; mental illness in the household; exposure to domestic violence) demonstrated a sex-specific impact on later criminal variety. In other words, two forms of household dysfunction did not significantly predict criminality for males (mental illness in the household; exposure to domestic violence) and one form of household dysfunction did not significantly predict criminality among females (incarcerated household member). Furthermore, while household substance abuse was a predictor of criminality across males and females, the effect size appears to be substantially higher across males $(\exp (\gamma)=1.28, p=.004)$ when compared to females $(\exp (\gamma)=1.17, p=.047)$.

According to Endendijk, Groeneveld, and Mesman (2018), children tend to receive a greater influence from the same-sex parental models. Girls are more likely to be encouraged and stimulated to imitate female role models, particularly mothers, while young boys are more likely to observe and imitate male role models, including fathers. Since incarceration (World Prison Brief, 2016) and substance abuse (McHugh, Votaw, Sugarman, \& Greenfield, 2018) are more prevalent among males, and parental psychopathology is more common among females (e.g., McKinney \& Stearns, 2021; Sun, Seeley, \& Allen, 2020), the sex-specific impact of parental models may be related to the gender-specific impacts on associations between childhood household dysfunction and later criminal behavior. However, this is a hypothesis that needs to be explored in further cross-national research.

Exposure to domestic violence perpetrated against the mother/stepmother was found to be associated with later criminal variety among young adult females, and among youths living in countries ranking lower in the HDI. This relationship did not hold for young adult males or young people living in countries ranking higher in the HDI. Although past studies have suggested stronger effects of exposure to domestic violence on girls' externalizing behaviors (e.g., Sternberg et al., 1993), more recent meta-analyses have reported very similar effect sizes across males and females (Moylan et al., 2010; Wilson et al., 2009).

Due to the cultural and linguistic homogeneity of previous studies, it is possible that the impact of exposure to domestic violence across sexes might be dependent on cultural and economic context. Children exposed to domestic violence and living in developing countries, or in countries where there is less social support for victims of domestic violence, might experience higher levels of negative emotions and be at increased risk of victimization (Peterman, Bleck, \& Palermo, 2015). Those negative emotions may include rage, hopelessness, and severe distress, resulting in more forms of aggressive and externalizing behavior (Agnew, 2006). In contrast, among boys exposed to domestic violence, these behaviors might be particularly learned as acceptable only in the specific context where it occurred (Akers, 2017), resulting in a higher likelihood of boys becoming perpetrators of domestic violence later in life. Nonetheless, there is a need for more intercultural studies to enhance our understanding of the role of gender on the impact of exposure to domestic violence on antisocial behavior.

Of note, four out of the five forms of childhood household dysfunction were found to be independent predictors of criminal variety among countries ranking lower in the HDI, but these results (with exception of household substance abuse) were not replicated among countries ranking higher in the HDI. HDI is one of the best indicators of national social well-being (Ngoo \& Tey, 2019). Thus, these discrepancies between countries may indicate that easier access to education, health services, and a better standard of living may work as protective factors for children and youth at risk, strengthening their social bonds (Sampson \& Laub, 2005) and helping to break the link between family dysfunction and later criminal behavior.

Finally, having experienced parental separation or divorce during childhood or adolescence was not a predictor of criminal variety during young adulthood. Separation or divorce can involve a significant readjustment in the life of families and is one of the most common forms of early adversity (e.g., Dube et al., 2003; Kessler et al., 2010). While meta-analyses have suggested a link between separation or divorce and posterior conduct problems (Amato, 2001), subsequent longitudinal studies have indicated that this link is moderated by family factors such as harsh discipline, child mental health problems and family economic struggle (Theobald, Farrington, \& Piquero, 2013). Since the model in the current study takes into account the most detrimental consequences of these moderators, such as physical neglect (e.g., economic struggle) and physical abuse (e.g., harsh discipline), any association between 
experience of separation or divorce during childhood may no longer hold.

\subsection{Strengths, limitations, and future research}

This study has several relevant strengths. This is the first large, cross-national study exploring the link between early adversity and criminal behavior during young adulthood, including participants from 10 countries with substantially different cultural, religious, and economic backgrounds. In addition, contrary to most studies analyzing data obtained from more than one country (e.g., metaanalyses or official records), this study used similar measures and methodologies across different countries. Studies using large samples to address female criminal behavior, particularly using cross-national designs, are extremely rare. This study provides new insights into the developmental process of criminal careers among females.

This study also contains some limitations. First, the sample was collected using a cross-national, non-probabilistic sampling methodology. This is a relevant limitation of this study. The decision to pursue this strategy is explained by implementation constraints such as the difficulty of gaining access to the entire list (or representative segment) of young adults in each country (e.g., Iraq, Brazil), and the prohibitive logistical obstacles and financial costs of a random representative sample collected in multiple geographic locations. To mitigate this limitation, the sample collected is homogenous regarding the developmental period examined (18-20 years old) and balanced regarding age within and between countries (Jager, Putnick, \& Bornstein, 2017). In addition, the analyses were conducted separately across genders, and according to the national level of HDI.

Notwithstanding the overall importance of probability sampling methods on provided an unbiased representative sample of the target population, in this field, apart from few studies using official records, studies with national representative samples are rare, and they are even less common across large cross-national studies (Jager et al., 2017; Nielsen, Haun, Kärtner, \& Legare, 2017). Establishing protocols between key governmental entities in each country (e.g., Ministry/Department of Justice), or through relevant international organizations (e.g., the United Nations; the World Health Organization), might help to overcome many of the barriers identified to the implementation of probability samples in cross-national studies.

Second, the number of countries included limits opportunity to test possible macro-level moderators that may explain the link between ACEs and criminal behavior. There is a need for future studies to include a larger range of countries from different parts of the globe.

Third, the data pertaining to ACEs and criminal behavior was obtained by retrospective self-reporting and may be vulnerable to inconsistency, underreporting or recall bias (e.g., Gomes, Farrington, Maia, \& Krohn, 2019). Although, self-reporting has been shown to be a stable and reliable method of data collection when confidentiality and anonymity is assured (Brener, Billy, \& Grady, 2003; Gomes et al., 2019; Piquero, Schubert, \& Brame, 2014), the combination of official cross-national data of childhood maltreatment and criminal behavior with self-report data would substantially strengthen this research. Thus, future cross-national studies should utilize data derived from both sources.

Fourth, while the ACE Questionnaire allowed the screening of different ACEs, it cannot capture the full extent of potentially traumatic events because it lacks important information about the chronicity of exposure to each ACE, the nature and intensity, or the developmental period of exposure to each one of those experiences (Anda, Porter, \& Brown, 2020; Basto-Pereira, Miranda, Ribeiro, \& Maia, 2016). In addition, some forms of adversity not assessed (e.g., exposure to community violence; emotional bullying) may underrepresent the nefarious impact of the typical 10 ACEs assessed across the ACE Questionnaire (McLennan, MacMillan, \& Afifi, 2020). Future research in this field could go beyond assessing the presence and type of childhood victimization, to understand the underlying knowledge about the context in which each one of these traumatic events occurred.

Finally, the impact of early adversity beyond child maltreatment is a topic deeply underexplored (Kerig \& Becker, 2015). Future longitudinal cross-cultural studies and meta-analyses could further examine how biological sex and culture shapes exposure and reaction to dysfunctional family environments during child development.

\subsection{Conclusions and implications for global policies}

This study adds significantly to the literature linking physical and sexual abuse and physical neglect to criminal behavior. Our findings suggest the impact of these forms of maltreatment are, to some extent, intercultural. They can undermine children's ability to timely and appropriately model behavior to cultural expectations, promoting antisocial behavior and other detrimental outcomes.

This study provides critical implications for global policies. Sexual abuse, physical abuse, and physical neglect appear to be important drivers for perpetuating the cycle of violence. Three approaches to reduce the deleterious effects of these forms of child maltreatment have been suggested. First, it is particularly important to increase the parental knowledge about child maturity and autonomy across ages, and to help parents to choose and develop, assertive and non-violent parenting strategies to correct child misbehavior. Second, international organizations can help local governments to establish effective strategies designed to support the children of families facing economic deprivation (e.g., school free meals). Third, it is also important to invest in the lifelong education and training of justice and social care professionals, helping them, more effectively to prevent and stop child maltreatment, and mitigate the potential consequences of early adversity. In this regard, it is important to highlight that, interventions and strategies addressing and preventing childhood adversity, in order to be effective and feasible, should always consider different norms, values, and economic realities in each country (Knerr, Gardner, \& Cluver, 2013).

Despite the range of negative outcomes linked to childhood household dysfunction, early adverse experiences not involving child maltreatment are usually ignored in local social policies. There is a need to support families around the world facing household difficulties (e.g., parental substance abuse, incarceration, mental illness) and related social stigma. Therefore, it is important to take 
measures to fight against discrimination and social exclusion of these families and ultimately break the cycle of ACEs and criminal behaviors for affected communities around the world.

\section{Acknowledgements}

We truly appreciate the insightful comments offered by the reviewers. This work is part of the International Study of Pro/Antisocial Behavior in Young Adults, an international collaborative research project. We give thanks to the institutions, individuals, and participants, who, in a way or another, made this cross-continental study possible.

\section{Declaration of competing interest}

The authors declare no conflicts of interest.

\section{References}

Agnew, R. (2006). Pressured into crime: An overview of general strain theory. California: OUP USA.

Akers, R. (2017). Social learning and social structure: A general theory of crime and deviance. New York: Routledge.

Amato, P. R. (2001). Children of divorce in the 1990s: An update of the Amato and Keith (1991) meta-analysis. Journal of Family Psychology, 15, 355-370. https://doi. org/10.1037/0893-3200.15.3.355

Anda, R. F., Porter, L. E., \& Brown, D. W. (2020). Inside the adverse childhood experience score: Strengths, limitations, and misapplications. American Journal of Preventive Medicine, 59(2), 293-295. https://doi.org/10.1016/j.amepre.2020.01.009

Baskin-Sommers, A. R., \& Baskin, D. (2016). Psychopathic traits mediate the relationship between exposure to violence and violent juvenile offending. Journal of Psychopathology and Behavioral Assessment, 38, 341-349. https://doi.org/10.1007/s10862-016-9535-0

Basto-Pereira, M., \& Maia, Â. (2017). Persistence in crime in young adults with a history of juvenile delinquency: The role of mental health and psychosocial problems. International Journal of Mental Health and Addiction, 16, 496-506. https://doi.org/10.1007/s11469-017-9847-7

Basto-Pereira, M., Miranda, A., Ribeiro, S., \& Maia, Â. (2016). Growing up with adversity: From juvenile justice involvement to criminal persistence and psychosocial problems in young adulthood. Child Abuse \& Neglect, 62, 63-75. https://doi.org/10.1016/j.chiabu.2016.10.011

Basto-Pereira, M., Queiroz-Garcia, I., Maciel, L., Leal, I., \& Gouveia-Pereira, M. (2020). An international study of pro/antisocial behavior in young adults. Cross Cultural Research, 54(1), 92-105. https://doi.org/10.1177/1069397119850741

Bater, L. R., \& Jordan, S. S. (2017). Child routines and self-regulation as serial mediators of parenting practices and externalizing problems in preschool children. Child \& Youth Care Forum, 46, 243-259. https://doi.org/10.1007/s10566-016-9377-7

Blair, R. J. R., \& Lee, T. M. (2013). The social cognitive neuroscience of aggression, violence, and psychopathy. Social Neuroscience, 8, 108-111. https://doi.org/ 10.1080/17470919.2012.757869

Bolker, B. M., Brooks, M. E., Clark, C. J., Geange, S. W., Poulsen, J. R., Stevens, M. H. H., \& White, J. S. S. (2009). Generalized linear mixed models: A practical guide for ecology and evolution. Trends in Ecology \& Evolution, 24, 127-135. https://doi.org/10.1016/j.tree. 2008.10.008

Braga, T., Cunha, O., \& Maia, A. (2018). The enduring effect of maltreatment on antisocial behavior: A meta-analysis of longitudinal studies. Aggression and Violent Behavior, 40, 91-100. https://doi.org/10.1016/j.avb.2018.04.003

Braga, T., Gonçalves, L. C., Basto-Pereira, M., \& Maia, A. (2017). Unraveling the link between maltreatment and juvenile antisocial behavior: A meta-analysis of prospective longitudinal studies. Aggression and Violent Behavior, 33, 37-50. https://doi.org/10.1016/j.avb.2017.01.006

Brener, N. D., Billy, J. O., \& Grady, W. R. (2003). Assessment of factors affecting the validity of self-reported health-risk behavior among adolescents: Evidence from the scientific literature. Journal of Adolescent Health, 33(6), 436-457. https://doi.org/10.1016/S1054-139X(03)00052-1

Carr, A., Duff, H., \& Craddock, F. (2020). A systematic review of reviews of the outcome of noninstitutional child maltreatment. Trauma, Violence, \& Abuse, 21(4), 828-843. https://doi.org/10.1177/1524838018801334

Condry, R. (2007). Families shamed: The consequences of crime for relatives of serious offenders. Cullompton: Willan Publishing.

Cottle, C. C., Lee, R. J., \& Heilbrun, K. (2001). The prediction of criminal recidivism in juveniles: A meta-analysis. Criminal Justice and Behavior, 28(3), 367-394. https://doi.org/10.1177/0093854801028003005

Dong, M., Anda, R. F., Felitti, V. J., Dube, S. R., Williamson, D. F., Thompson, T. J., \& Giles, W. H. (2004). The interrelatedness of multiple forms of childhood abuse, neglect, and household dysfunction. Child Abuse \& Neglect, 28(7), 771-784. https://doi.org/10.1016/j.chiabu.2004.01.008

Douglas, K., Chan, G., Gelernter, J., Arias, A. J., Anton, R. F., Poling, J., Farrer, L., \& Kranzler, H. R. (2011). 5-HTTLPR as a potential moderator of the effects of adverse childhood experiences on risk of antisocial personality disorder. Psychiatric Genetics, 21(5), 240-248. https://doi.org/10.1097/YPG.0b013e3283457c15

Dube, S. R., Felitti, V. J., Dong, M., Chapman, D. P., Giles, W. H., \& Anda, R. F. (2003). Childhood abuse, neglect, and household dysfunction and the risk of illicit drug use: The adverse childhood experiences study. Pediatrics, 111, 564-572. https://doi.org/10.1542/peds.111.3.564

Endendijk, J. J., Groeneveld, M. G., \& Mesman, J. (2018). The gendered family process model: An integrative framework of gender in the family. Archives of Sexual Behavior, 47(4), 877-904. https://doi.org/10.1007/s10508-018-1185-8

Farrington, D. P. (2015). Cross-national comparative research on criminal careers, risk factors, crime and punishment. European Journal of Criminology, 12(4), 386-399. https://doi.org/10.1177/1477370815584262

Felson, R. B., \& Lane, K. J. (2009). Social learning, sexual and physical abuse, and adult crime. Aggressive Behavior, 35, 489-501. https://doi.org/10.1002/ab.20322

Fitton, L., Yu, R., \& Fazel, S. (2020). Childhood maltreatment and violent outcomes: A systematic review and meta-analysis of prospective studies. Trauma Violence Abuse, 21(4), 754-768. https://doi.org/10.1177/1524838018795269

Flanagan, I. M., Auty, K. M., \& Farrington, D. P. (2019). Parental supervision and later offending: A systematic review of longitudinal studies. Aggression and Violent Behavior, 47, 215-229. https://doi.org/10.1016/j.avb.2019.06.003

Galler, J. R., Bryce, C. P., Waber, D. P., Medford, G., Eaglesfield, G. D., \& Fitzmaurice, G. (2011). Early malnutrition predicts parent reports of externalizing behaviors at ages 9-17. Nutritional Neuroscience, 14(4), 138-144. https://doi.org/10.1179/147683011x13009738172521

Gauffin, K., Hjern, A., Vinnerljung, B., \& Björkenstam, E. (2016). Childhood household dysfunction, social inequality and alcohol related illness in young adulthood. A Swedish National Cohort Study. PloS one, 11(3), Article e0151755. https://doi.org/10.1371/journal.pone.0151755

Glenn, A. L. (2019). Early life predictors of callous-unemotional and psychopathic traits. Infant Mental Health Journal, 40, 39-53. https://doi.org/10.1002/imhj.21757

Gomes, H., \& Gouveia-Pereira, M. (2020). Testing the general theory of crime with the circumplex model: Curvilinear relations between family functioning and selfcontrol. Deviant Behavior, 41(6), 779-791. https://doi.org/10.1080/01639625.2019.1596449

Gomes, H. S., Farrington, D. P., Maia, Â., \& Krohn, M. D. (2019). Measurement bias in self-reports of offending: A systematic review of experiments. Journal of Experimental Criminology, 15, 313-339. https://doi.org/10.1007/s11292-019-09379-w

Heck, R. H., Thomas, S., \& Tabata, L. (2013). Multilevel modeling of categorical outcomes using IBM SPSS. New York: Routledge.

Hillis, S. D., Anda, R. F., Dube, S. R., Felitti, V. J., Marchbanks, P. A., \& Marks, J. S. (2004). The association between adolescent pregnancy, longterm psychosocial outcomes, and fetal death. Pediatrics, 113, 320-327. https://doi.org/10.1542/peds.113.2.320

Jager, J., Putnick, D. L., \& Bornstein, M. H. (2017). II. More than just convenient: The scientific merits of homogeneous convenience samples. Monographs of the Society for Research in Child Development, 82(2), 13-30. https://doi.org/10.1111/mono.12296 
Kerig, P. K., \& Becker, S. P. (2015). Early abuse and neglect as risk factors for the development of criminal and antisocial behavior. In J. Morizot, \& L. Kazemian (Eds.), The development of criminal and antisocial behavior: Theoretical foundations and practical applications (pp. 181-199). London: Springer.

Kessler, R. C., McLaughlin, K. A., Green, J. G., Gruber, M. J., Sampson, N. A., Zaslavsky, A. M., \& Williams, D. R. (2010). Childhood adversities and adult psychopathology in the WHO World Mental Health Surveys. British Journal of Psychiatry, 197(5), 378-385. https://doi.org/10.1192/bjp.bp.110.080499

Knerr, W., Gardner, F., \& Cluver, L. (2013). Improving positive parenting skills and reducing harsh and abusive parenting in low- and middle-income countries: A systematic review. Prevention Science, 14, 352-363.

Kochanska, G., \& Kim, S. (2012). Toward a new understanding of legacy of early attachments for future antisocial trajectories: Evidence from two longitudinal studies. Development and Psychopathology, 24(3), 783-806. https://doi.org/10.1017/S0954579412000375

Larkin, H., Shields, J. J., \& Anda, R. F. (2012). The health and social consequences of adverse childhood experiences (ACE) across the lifespan: An introduction to prevention and intervention in the community. Journal of Prevention \& Intervention in the Community, 40, 263-270. https://doi.org/10.1080/ 10852352.2012 .707439

Leban, L., \& Gibson, C. L. (2020). The role of gender in the relationship between adverse childhood experiences and delinquency and substance use in adolescence. Journal of Criminal Justice, 66(101637), 1-11. https://doi.org/10.1016/j.jcrimjus.2019.101637

McHugh, R. K., Votaw, V. R., Sugarman, D. E., \& Greenfield, S. F. (2018). Sex and gender differences in substance use disorders. Clinical Psychology Review, 66, $12-23$. https://doi.org/10.1016/j.cpr.2017.10.012

McKinney, C., \& Stearns, M. (2021). Parental psychopathology and oppositional defiant problems in emerging adults: Moderated mediation by temperament and gender. Child Psychiatry \& Human Development, 52(3), 439-449. https://doi.org/10.1007/s10578-020-01030-4

McLean, L. M., \& Gallop, R. (2003). Implications of childhood sexual abuse for adult borderline personality disorder and complex posttraumatic stress disorder. American Journal of Psychiatry, 160(2), 369-371. https://doi.org/10.1176/appi.ajp.160.2.369

McLennan, J. D., MacMillan, H. L., \& Afifi, T. O. (2020). Questioning the use of adverse childhood experiences (ACES) questionnaires. Child Abuse \& Neglect, 101, Article 104331. https://doi.org/10.1016/j.chiabu.2019.104331

Moylan, C. A., Herrenkohl, T. I., Sousa, C., Tajima, E. A., Herrenkohl, R. C., \& Russo, M. J. (2010). The effects of child abuse and exposure to domestic violence on adolescent internalizing and externalizing behavior problems. Journal of Family Violence, 25, 53-63. https://doi.org/10.1007/s10896-009-9269-9

Ngoo, Y. T., \& Tey, N. P. (2019). Human development index as a predictor of life satisfaction. Journal of Population and Social Studies, 27(1), 70-86. https://doi.org/ $10.25133 / J P S S v 27 n 1.005$

Nielsen, M., Haun, D., Kärtner, J., \& Legare, C. H. (2017). The persistent sampling bias in developmental psychology: A call to action. Journal of Experimental Child Psychology, 162, 31-38. https://doi.org/10.1016/j.jecp.2017.04.017

Papalia, N., Ogloff, J. R. P., Cutajar, M., \& Mullen, P. E. (2018). Child sexual abuse and criminal offending: Gender-specific effects and the role of abuse characteristics and other adverse outcomes. Child Maltreatment, 23(4), 399-416. https://doi.org/10.1177/1077559518785779

Paz-Alonso, P. M., \& Goodman, G. S. (2008). Trauma and memory: Effects of post-event misinformation, retrieval order, and retention interval. Memory, 16, 58-75.

Peterman, A., Bleck, J., \& Palermo, T. (2015). Age and intimate partner violence: An analysis of global trends among women experiencing victimization in 30 developing countries. Journal of Adolescent Health, 57(6), 624-630.

Piquero, A. R., Schubert, C. A., \& Brame, R. (2014). Comparing official and self-report records of offending across gender and race/ethnicity in a longitudinal study of serious youthful offenders. Journal of Research in Crime and Delinquency, 51(4), 526-556. https://doi.org/10.1177/0022427813520445

Rizopoulos, W. (2020). GLMMadaptive: Generalized Linear Mixed Models using Adaptive Gaussian Quadrature [Computer software manual. https://cran.r-project. org/web/packages/GLMMadaptive/GLMMadaptive.pdf (R package v.0.7-15).

Sampson, R. J., \& Laub, J. H. (2005). A life-course view of the development of crime. The Annals of the American Academy of Political and Social Science, $602(1), 12-45$. https://doi.org/10.1177/0002716205280075

Sanches, C., Gouveia-Pereira, M., Marôco, J., Gomes, H., \& Roncon, F. (2016). Deviant Behavior Variety Scale: Development and validation with a sample of Portuguese adolescents. Psicologia: Reflexão e Crítica, 29(31), 1-8. https://doi.org/10.1186/s41155-016-0035-7

Sternberg, K. J., Lamb, M. E., Greenbaum, C., Cicchetti, D., Dawud, S., Cortes, R. M., Krispin, O., \& Lorey, F. (1993). Effects of domestic violence on children's behavior problems and depression. Developmental Psychology, 29, 44-52. https://doi.org/10.1037/0012-1649.29.1.44

Stoltenborgh, M., Bakermans-Kranenburg, M. J., Alink, L. R., \& van IJzendoorn, M. H. (2015). The prevalence of child maltreatment across the globe: Review of a series of meta-analyses. Child Abuse Review, 24, 37-50. https://doi.org/10.1002/car.2353 (R package v.0.7-15).

Stolzenberg, L., \& D'Alessio. (2008). Co-offending and the age-crime curve. Journal of Research in Crime and Delinquency, 45, 65-86. https://doi.org/10.1177/ 0022427807309441

Sun, X., Seeley, J. R., \& Allen, N. B. (2020). Parental internalizing disorder and the developmental trajectory of infant self-regulation: The moderating role of positive parental behaviors. In Development and psychopathology (pp. 1-17). https://doi.org/10.1017/S0954579420001042. Advance online publication.

Swan, S. C., Gambone, L. J., Fields, A. M., Sullivan, T. P., \& Snow, D. L. (2005). Women who use violence in intimate relationships: The role of anger, victimization, and symptoms of posttraumatic stress and depression. Violence and Victims, 20(3), 267-285. https://doi.org/10.1891/vivi.20.3.267

Theobald, D., Farrington, D. P., \& Piquero, A. R. (2013). Childhood broken homes and adult violence: An analysis of moderators and mediators. Journal of Criminal Justice, 41, 44-52. https://doi.org/10.1016/j.jcrimjus.2012.12.003

Tyler, K. A., Hoyt, D. R., Whitbeck, L. B., \& Cauce, A. M. (2001). The impact of childhood sexual abuse on later sexual victimization among runaway youth. Journal of Research on Adolescence, 11(2), 151-176. https://doi.org/10.1111/1532-7795.00008

Ullman, S. E., \& Filipas, H. H. (2005b). Gender differences in social reactions to abuse disclosures, post-abuse coping, and PTSD of child sexual abuse survivors. Child Abuse \& Neglect, 29(7), 767-782. https://doi.org/10.1016/j.chiabu.2005.01.005

United Nations Development Programme (UNDP). (2019). Human Development Report 2019: Beyond income, beyond averages, beyond today: Inequalities in human development in the 21st century. HDRO (Human Development Report Office). http://www.hdr.undp.org/sites/default/files/hdr2019.pdf.

Widom, C. S. (1989). Child abuse, neglect and adult behavior: Research design and findings on criminality, violence, and child abuse. American Journal of Orthopsychiatry, 59, 355-367. https://doi.org/10.1111/j.1939-0025.1989.tb01671.x

Wilson, H. W., Stover, C. S., \& Berkowitz, S. J. (2009). Research review: The relationship between childhood violence exposure and juvenile antisocial behavior: A meta-analytic review. Journal of Child Psychology and Psychiatry, 50, 769-779. https://doi.org/10.1111/j.1469-7610.2008.01974.x

World Health Organization. (2020, 22 October). Violence against children. https://www.who.int/health-topics/violence-against-children\#tab=tab_1.

World Prison Brief. (2016). World Prison Population List (11th ed.). Institute for Criminal Policy Research.

Young-Southward, G., Svelnys, C., Gajwani, R., Enlow, M. B., \& Minnis, H. (2020). Child maltreatment, autonomic nervous system responsivity, and psychopathology: Current state of the literature and future directions. Child Maltreatment, 25, 3-19. https://doi.org/10.1177/1077559519848497 